Article

\title{
Comparison between a Water-Based and a Solvent-Based Impregnation Method towards Dispersed CuO/SBA-15 Catalysts: Texture, Structure and Catalytic Performance in Automotive Exhaust Gas Abatement
}

\author{
Qi Xin ${ }^{1, *}$, Antonella Glisenti ${ }^{2}$, Constantine Philippopoulos ${ }^{3}$, Evangelos Poulakis ${ }^{3}$, \\ Myrjam Mertens ${ }^{4}$, Jeff L. Nyalosaso ${ }^{1}$, Vera Meynen ${ }^{1}$ and Pegie Cool ${ }^{1}$ \\ 1 Laboratory of Adsorption \& Catalysis, University of Antwerp, Universiteitsplein 1, 2610 Wilrijk, Belgium; \\ jnyalosaso@sigma-clermont.fr (J.L.N.); vera.meynen@uantwerpen.be (V.M.); \\ pegie.cool@uantwerpen.be (P.C.) \\ 2 Dipartimento di Scienze Chimiche, Università degli Studi di Padova, Via F. Marzolo, 1, 35131 Padova, Italy; \\ antonella.glisenti@unipd.it \\ 3 Chemical Process Engineering Laboratory, Department of Chemical Engineering, \\ National Technical University of Athens, 9 Heroon Polytechniou Str., Zografos Camphs, 15780 Athens, \\ Greece; kphilip@chemeng.ntua.gr (C.P.); poulakis.txd@gmail.com (E.P.) \\ 4 Flemish Institute for Technological Research (VITO N.V.), Boeretang 200, 2400 Mol, Belgium; \\ myrjam.mertens@vito.be \\ * Correspondence: qi.xin@uantwerpen.be; Tel.: +32-3-265-2354
}

Academic Editor: Jean-François Lamonier

Received: 6 September 2016; Accepted: 14 October 2016; Published: 21 October 2016

\begin{abstract}
Supported copper oxide nanoparticles are a potential candidate for replacing the rare and expensive precious metals within the automotive three-way catalyst. However, a well-designed dispersion method is necessary to allow a stable high loading of active material, compensating its lower intrinsic activity and stability. In this work, a CuO-loaded SBA-15 catalyst has been manufactured by two methods. The ammonia-driven deposition precipitation (ADP) and the molecular designed dispersion (MDD) methods are both considered as efficient deposition methods to provide well-dispersed copper oxide-based catalysts. Their morphology, copper dispersion and the chemical state of copper were characterized and compared. Due to the differences in the synthesis approach, a difference in the obtained copper oxide phases has been observed, leading to a distinct behavior in the catalytic performance. The structure-activity correlation of both catalysts has also been revealed for automotive exhaust gas abatement. Results demonstrate that various copper species can be formed depending on the precursor-support interaction, affecting selectivity and conversion during the catalytic reaction.
\end{abstract}

Keywords: copper; ammonia based impregnation; molecular designed dispersion; three-way catalyst

\section{Introduction}

Automotive three-way catalysts (TWC) based on $\mathrm{Pt}, \mathrm{Pd}$ and $\mathrm{Rh}$ have been designed and manufactured with the objective to improve air quality and protect human health. The presence of the platinum group metals (PGMs) provides a distinguishing effectiveness for the conversion of hydrocarbons (HCs), carbon monoxide (CO) and nitrogen oxides $\left(\mathrm{NO}_{x}\right)$ [1,2]. Furthermore, their outstanding stability guarantees a long catalyst on-road life span. Despite aforementioned advantages, the rising issue of PGMs is their increasing scarcity and, consequently, their high cost [3]. Hence, 
looking for other sustainable and economically beneficial alternatives is now a major priority and challenge for the automotive catalyst industry [4].

In this context, copper-based heterogeneous catalysts are a potential candidate for replacing Pd and $\mathrm{Pt}$ for vehicular oxidation of $\mathrm{CO}$ and HCs [5]. During the last decades, this type of catalyst has drawn a considerable amount of attention because of its remarkable redox activity, high recyclability and low cost [6,7]. This leads to its application in various reactions, for instance hydrogenolysis of glycerol to 1,2-propanediol [8-10], hydrogenation of dimethyl oxalate [11-13] and methanol synthesis [14-16]. However, in order to use copper as an active element for automotive emission control, two major limitations should be considered and overcome. First is its low intrinsic activity: copper has an activity that is 50 times lower than that of Pd for CO oxidation and even 100 times lower than that of $\mathrm{Pt}$ for HCs conversion [7]. Secondly, the high reaction temperature within the vehicle (up to $800{ }^{\circ} \mathrm{C}$ ) will accelerate the catalyst's deactivation by the means of particle growth, leading to a low catalyst durability $[17,18]$. Literature suggests that these drawbacks can be mitigated by providing a well-designed deposition method with small and highly dispersed copper oxide nanoparticles decorating the substrate, which will enhance the active sites' surface and suppress the particle agglomeration $[19,20]$.

In the past, the molecular designed dispersion (MDD) method, based on the impregnation of metal acetylacetonate (acac) complexes on silica and alumina surfaces, was investigated and optimized [21-24]. The main principle of this method relies on the steric effect of the large acac ligands in the precursor, which guarantees a large spatial distance among the metal atoms during impregnation. The overall result is a catalyst with a highly dispersed copper oxide phase on the material's surface. Studies show that during the complex deposition, interactions between the acac complex and the surface hydroxyl group of the support will be established [24]. These interactions determine the success of the whole synthesis since it restricts the metal atoms' mobility during the ligand removal step at high temperature. Despite these benefits, an important drawback of this method is the need to work in a water-free environment with non- or weak- surface interacting solvents to prevent competitive adsorption and warrant sufficient loading. This makes the method less environmentally friendly and more difficult for further industrial upscaling.

For this reason, we recently adapted and optimized a water-based method, the so-called ammonia-driven deposition precipitation (ADP), described by Guo et al. as a more eco-friendly alternative for copper-based catalyst preparation [25]. The concept of this approach relies on ammonia addition during the copper impregnation. Herein, the formed copper-ammonia complex replaces the metal acetylacetonate complex in its role as a steric hindrance provider. Furthermore, because of the ammonia addition, the $\mathrm{pH}$ of the solution $(\mathrm{pH} \approx 10)$ rises far above the point of zero charge (PZC) of the support $(\approx 2$ for silica), creating a strong electrostatic complex-support interaction during the synthesis [26,27].

Although considerable research has demonstrated the effectiveness of both methods to provide well-dispersed copper oxide nanoparticles onto the catalyst support [23,28,29], less attention has been paid to the differences in the copper oxide formation and consequently their structural properties. Hence, the influence of these differences on the catalytic performance remains to be shown. In the present work, we applied both approaches for the preparation of a CuO/SBA- 15 catalyst. The emphasis lies on the identification and comparison of the different $\mathrm{CuO}$ species formed by these deposition methods. Finally, the structure-activity relationship of both catalysts was elucidated by evaluating them for the automotive exhaust gas conversion.

\section{Results}

\subsection{Textural Properties}

Textural properties of the synthesized catalysts were characterized using $\mathrm{N}_{2}$-sorption analysis. The respective isotherms are illustrated in Figure 1. As a reference, the isotherm of the pure SBA-15 
is also shown in the figure. The pure SBA-15 silica support demonstrates a typical type IV isotherm according to the International Union of Pure and Applied Chemistry (IUPAC) classification [30], accompanied by a $\mathrm{H} 1$ type of hysteresis, referring to a porous material consisting of well-defined cylindrical-like pore channels. The presence of material's micro-porosity is derived by an initial uptake at low relative pressure $\left(P / P_{0} \approx 0.075\right)$, while a steep capillary condensation at $P / P_{0} \approx 0.75$ is associated with a high pore size uniformity of $6.2 \mathrm{~nm}$ (determined by the Barret-Joyner-Halenda method). After metal deposition, the shape of the hysteresis loop did not change for both catalysts, suggesting an effective impregnation of metal nanoparticles without pore blockage [29]. However, other properties did change: Table 1 gives an overview of the materials' textural parameters derived from their isotherms. The drastic loss of surface area of about $20 \%$ for the MDD sample and of more than $40 \%$ for the ADP sample indicates the presence of copper oxide within the micropores and mesopores of the support. Although the micropores are blocked and no longer accessible, the mesopores are still reachable. The existence of copper oxide particles inside the mesopores is advantageous for the copper oxide dispersion, since pore confinement will prevent further metal oxide particle growth within the pores [31]. Finally, when comparing the average pore size of the materials, a significant increase can be recognized for the ADP sample. This seems to originate from the dissolution of the silica's outer layer in the pore, accomplished by the high solution $\mathrm{pH}(\approx 11)$ of the ADP method [27]. Despite the significant loss in surface area and pore size increase due to this dissolution under basic conditions, the pore shape of the ADP sample remains intact with a pore volume comparable to that of the MDD sample.

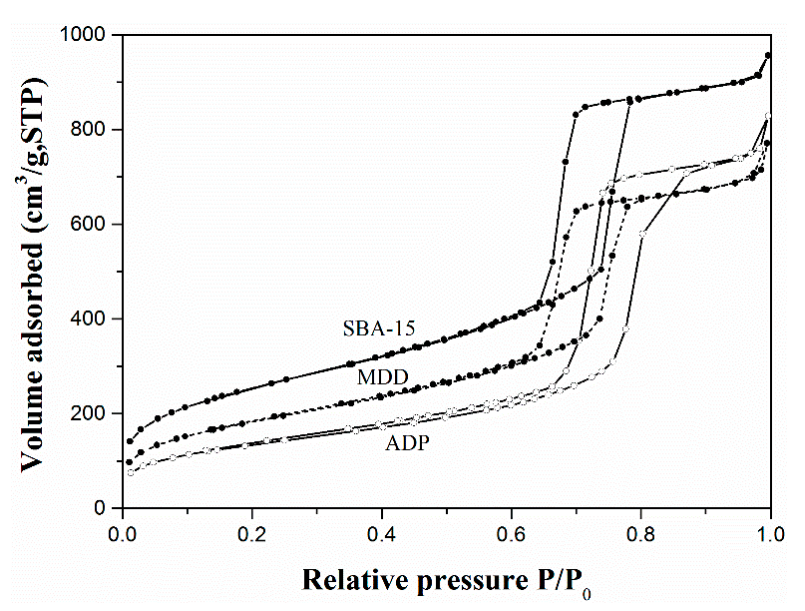

Figure 1. $\mathrm{N}_{2}$-physisorption isotherms of SBA-15 and CuO/SBA-15 catalysts prepared by molecular designed dispersion (MDD) and ammonia-driven deposition precipitation (ADP) methods.

Table 1. Textual properties and copper loading of CuO/SBA-15 catalysts.

\begin{tabular}{|c|c|c|c|c|c|c|}
\hline \multirow[b]{2}{*}{ Sample } & \multicolumn{5}{|c|}{ Porosity } & \multirow{2}{*}{$\begin{array}{c}\text { Metal Composition } \\
\mathrm{Cu}(\mathrm{wt} \%)\end{array}$} \\
\hline & $\begin{array}{c}S_{\mathrm{BET}}{ }^{1} \\
\left(\mathrm{~m}^{2} \cdot \mathrm{g}^{-1}\right)\end{array}$ & $\begin{array}{c}V_{\text {meso }}{ }^{2} \\
\left(\mathrm{~cm}^{3} \cdot \mathrm{g}^{-1}\right)\end{array}$ & $\begin{array}{c}V_{\text {micro }}{ }^{3} \\
\left(\mathrm{~cm}^{3} \cdot \mathrm{g}^{-1}\right)\end{array}$ & $\begin{array}{c}V_{\text {Total }}{ }^{4} \\
\left(\mathrm{~cm}^{3} \cdot \mathrm{g}^{-1}\right)\end{array}$ & $\begin{array}{l}d_{\mathrm{p}}^{5} \\
(\mathrm{~nm})\end{array}$ & \\
\hline SBA-15 & 910 & 1.35 & 0.061 & 1.41 & 6.2 & - \\
\hline $\mathrm{MDD}^{6}$ & 737 & 1.36 & 0.010 & 1.37 & 6.7 & 7.1 \\
\hline $\mathrm{ADP}^{7}$ & 537 & 1.30 & 0.011 & 1.31 & 9.7 & 9.8 \\
\hline
\end{tabular}

${ }^{1}$ Brunauer-Emmett-Teller (BET) surface area of the support only, excluding the weight of copper; ${ }^{2}$ mesopore volume; ${ }^{3}$ micropore volume via t-plot method; ${ }^{4}$ total pore volume determined at $P / P_{0}=0.95 ;{ }^{5}$ average pore diameter by applying the Barret-Joyner-Halenda method (BJH) to the adsorption branch of the isotherm; ${ }^{6} \mathrm{MDD}$, molecular designed dispersion; ${ }^{7} \mathrm{ADP}$, ammonia-driven deposition precipitation.

\subsection{Copper Oxide Dispersion}

Figure 2 shows the $\mathrm{X}$-ray diffraction (XRD) curves of the $\mathrm{CuO} / \mathrm{SBA}-15$ catalyst prepared by the $\mathrm{MDD}$ and ADP methods. For the MDD sample, the diffraction peaks characteristic for $\mathrm{CuO}$ crystallites 
cannot be resolved in the diffractograms. On the other hand, the ADP sample shows very weak $\mathrm{CuO}$ peaks which are in proximity to the detection limit of the instrument. Since the XRD technique can only detect the crystallites within the material that are larger than a certain size, it is most likely that the copper oxide species on the materials are present in the form of amorphous/well-dispersed $\mathrm{CuO}$. Herein, the term well-dispersed $\mathrm{CuO}$ is defined as non-XRD-detectable, small copper particles. However, they can still possess divergent dimensions, which will be further identified through other techniques.

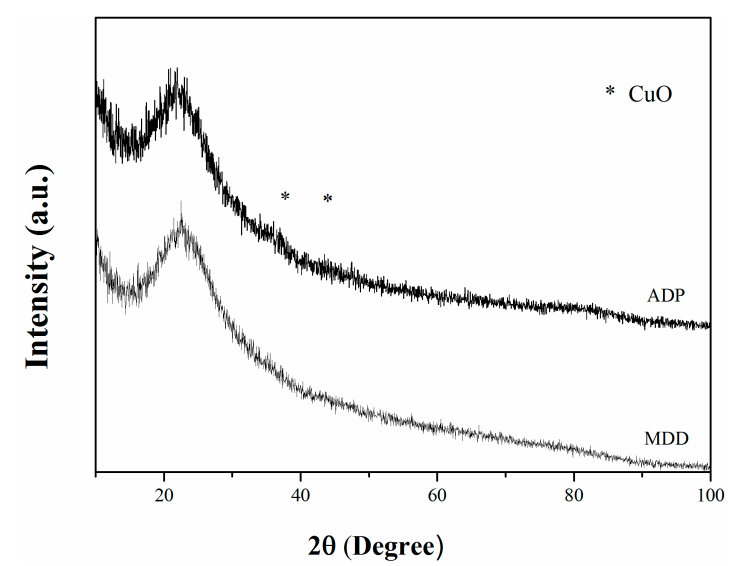

Figure 2. X-ray diffraction patterns of the CuO/SBA-15 materials prepared by ADP method (top) and MDD method (bottom).

Evidently, the information provided by XRD analysis is in our case very limited for gaining a good insight in the copper oxide dispersion. For this reason, $\mathrm{X}$-ray photoelectron spectroscopy (XPS) analysis was performed with the aim to identify the oxidation state of copper on the catalytic surface. The $\mathrm{Cu} 2 \mathrm{p}_{3 / 2}$ core level peak is illustrated in Figure 3. In all samples, the copper is in an oxidation state of $\mathrm{Cu}^{2+}$, evidenced by the characteristic shake-up satellite peak centered at $943.8 \mathrm{eV}$. However, by comparing both spectra, some obvious differences can be noticed. The $\mathrm{Cu} 2 \mathrm{p}_{3 / 2}$ signal, situated between 933.5 and $936.0 \mathrm{eV}$, can be deconvoluted into two peaks centered at 933.7 and $935.9 \mathrm{eV}$, respectively. The peak at a lower binding energy (BE) is attributed to the $\mathrm{CuO}$ species distributed on the surface, while the peak at a higher BE can be due to the formation of copper hydroxyl groups or to the interaction with the neighboring $\mathrm{Si}-\mathrm{O}$ bonds. Toupance et al. reported the existence of two types of well-dispersed $\mathrm{Cu}^{2+}$ species when using the ammonia-based method for metal impregnation, i.e., copper phyllosilicate and grafted $\mathrm{Cu}^{2+}$ [27]. Copper phyllosilicate has a lamellar structure wherein the layers of $\mathrm{SiO}_{4}$ tetrahedra are sandwiched between discontinuous layers of $\mathrm{CuO}_{6}$ octahedra [27,32]. It is a result of the hetero-condensation reaction between the $\mathrm{Cu}(\mathrm{OH})_{2}\left(\mathrm{H}_{2} \mathrm{O}\right)_{4}$ and the silicic acid $\left(\mathrm{Si}(\mathrm{OH})_{4}\right)$ formed by the silica dissolution at basic $\mathrm{pH}[11,27,33]$. The latter phenomenon is in line with the support's pore enlargement observed in the ADP sample by the $\mathrm{N}_{2}$ physisorption (Table 1). In contrast, the grafted $\mathrm{Cu}^{2+}$, in the form of $\mathrm{Cu}-\mathrm{O}-\mathrm{Si}$, is formed due to the ion exchange between two surface silanol groups and the $\mathrm{Cu}^{2+}$ ion. Since both phyllosilicate and grafted copper have a strong interaction towards the support matrix, it suggests that the signal at $935.9 \mathrm{eV}$ is likely to have a contribution of both copper oxides on the surface. On the contrary, the existence of copper phyllosilicate is less probable in the MDD sample, since its synthesis is conducted under an aqueous-free environment. In other words, the signal at $935.9 \mathrm{eV}$ for the MDD sample is related to the formation of copper hydroxyl or copper oxide which is grafted on the material due to the covalent $\mathrm{Me}-\mathrm{O}_{\text {support }}$ bond (Section 2.3). Another detail worth mentioning is the relative low intensity of the shake-up satellite at $943.8 \mathrm{eV}$ for the MDD sample, which points out that a small part of the copper species are reduced. However, considering that the sample was thermally treated under air atmosphere, these reduced $\mathrm{Cu}$ species are more likely to be in the $\mathrm{Cu}^{+}$and not in the $\mathrm{Cu}^{0}$ state. 


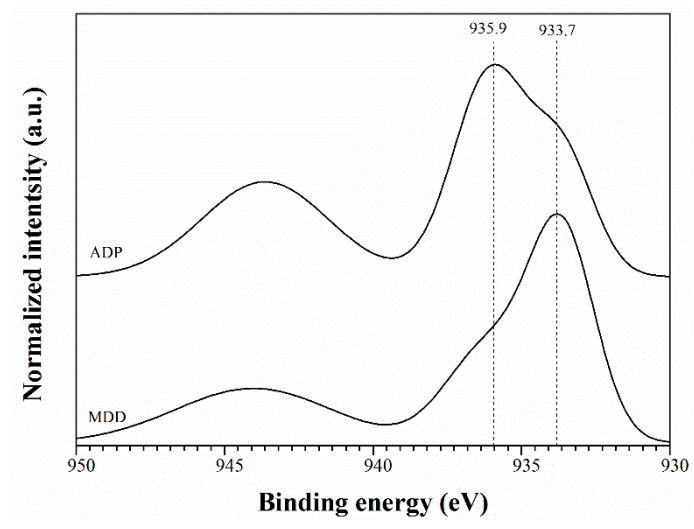

Figure 3. X-ray photoelectron spectroscopy (XPS) spectra of $\mathrm{Cu} 2 \mathrm{p}_{3 / 2}$ region for the CuO/SBA-15 sample prepared by ADP method (top) and MDD method (bottom).

Temperature programmed reduction (TPR) analysis has been implemented in this investigation in order to identify the dispersion state and the reduction behavior of the catalysts. The $\mathrm{H}_{2}$-TPR profiles of the calcined samples are shown in Figure 4. As a reference, the profile of a bulk $\mathrm{CuO}$ sample is also shown in the figure. For the MDD sample, two types of $\mathrm{CuO}$ can be distinguished: a phase of copper-oxo-cations indicated by the peak centered at $200{ }^{\circ} \mathrm{C}$ and the well-dispersed copper oxide species at $215^{\circ} \mathrm{C}[34,35]$. Moreover, the fact that no reduction activity is visible above $300{ }^{\circ} \mathrm{C}$ suggests the absence of bulk $\mathrm{CuO}$, in line with the observation from its XRD pattern. When compared with the ADP sample, one can clearly observe its higher temperature requirement for the $\mathrm{CuO}$ reduction. The main reduction of the ADP sample took place at $270{ }^{\circ} \mathrm{C}$ which is $55^{\circ} \mathrm{C}$ higher than the reduction of the MDD sample. The higher reduction temperature indicates a higher energy requirement for the metal reduction which is in our case caused by the strong metal-support interaction, as evidenced by the XPS result. Besides this, various literature reports suggest that a strong metal-support interaction often results in smaller metal oxide particles since it suppresses their mobility [14,36]. Hence, it is reasonable to believe that the well-dispersed $\mathrm{CuO}$ particles on the ADP sample (both phyllosilicate and grafted copper) exhibit smaller particle size than the MDD particles, although both are below the detection limit of the XRD. Additionally, this $\mathrm{H}_{2}$-TPR profile illustrates also a certain asymmetry of this reduction peak caused by two small reduction shoulders on its left $\left(\approx 250^{\circ} \mathrm{C}\right)$ and right $\left(\approx 310^{\circ} \mathrm{C}\right)$ side. The shoulder at $250{ }^{\circ} \mathrm{C}$ indicates the presence of well-dispersed $\mathrm{CuO}$ loosely bonded on the surface because of its lower reduction energy requirement. On the other hand, the reduction signal at the right side is representative for larger $\mathrm{CuO}$, as evidenced by the TPR profile of the bulk $\mathrm{CuO}$ (Figure 4, bottom) and its weak $\mathrm{CuO}$ diffraction peak on the XRD spectra (Figure 2).

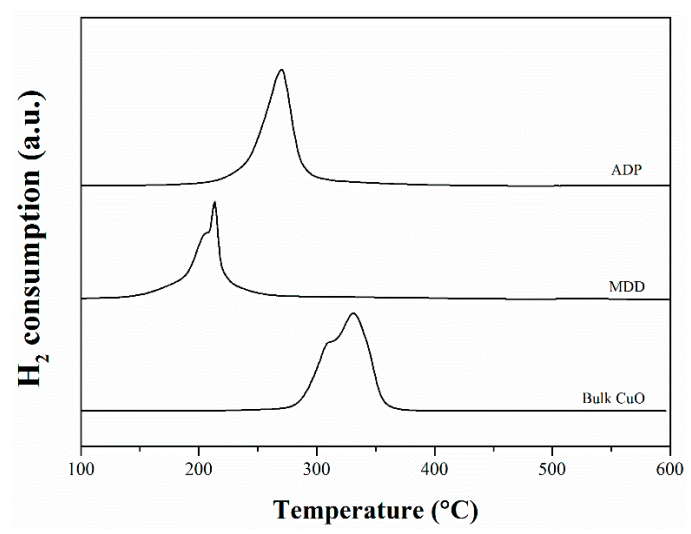

Figure 4. $\mathrm{H}_{2}$-TPR (temperature programmed reduction) profile of the $\mathrm{CuO} / \mathrm{SBA}-15$ materials prepared by ADP (top) and MDD (middle) methods and the bulk $\mathrm{CuO}$ (bottom). 
Based on the $\mathrm{H}_{2}$-TPR results of both samples, it can be concluded that both materials exhibit a superior copper dispersion upon the support accomplished by the well-designed dispersion methods. However, it is clear that these well-dispersed copper oxides have a significant difference in their structural property and metal-support interaction, leading to their unique reduction behavior. To further elucidate the structural differences of the copper phases, UV-Vis diffuse reflectance (UV-Vis-DR) measurements were carried out. The UV-Vis-DR spectra of the samples are shown in Figure 5. Generally, the signals can be divided into three regions ranging between $230-300 \mathrm{~nm}$, $300-500 \mathrm{~nm}$ and $600-800 \mathrm{~nm}$. The band situated at 230-300 $\mathrm{nm}$ has been assigned to the charge transfer between mononuclear $\mathrm{Cu}^{2+}$ and oxygen [28,37], whereas the band at $300-500 \mathrm{~nm}$ has been attributed to the presence of $[\mathrm{Cu}-\mathrm{O}-\mathrm{Cu}]_{n}$-type clusters (oligomeric species) different from the bulk $\mathrm{CuO}$ [23]. Finally, the signal at 600-800 nm corresponds to the $\mathrm{d}-\mathrm{d}$ transition of $\mathrm{Cu}^{2+}$ situated in an octahedral environment, which is, in other words, the typical band for bulk $\mathrm{CuO}$ [37]. For both MDD and ADP samples, the copper signals are mainly situated between the region of monomeric and oligomeric species while only a low intensity of the bulk $\mathrm{CuO}$ band is present. This observation suggests the high copper oxide dispersion on the materials with a small amount of larger $\mathrm{CuO}$, in line with the $\mathrm{H}_{2}$-TPR results. However, as demonstrated by the previous results, the well-dispersed copper oxide on both materials is a compilation of different copper oxide species, which can be clearly observed here. The ADP sample contains mainly mononuclear $\mathrm{CuO}$ species in the 230-300 $\mathrm{nm}$ region and only a small percentage are present in the 300-500 $\mathrm{nm}$ region, while the MDD sample has both mononuclear and oligomeric $\mathrm{CuO}$ visible with a broad superimposed UV-DR signal up to $550 \mathrm{~nm}$. When analyzing the results in more detail, it can be noticed that the band ranging between 230 and $300 \mathrm{~nm}$ of both samples can be deconvoluted into two separate signals, located respectively at 246 and $276 \mathrm{~nm}$ for the ADP sample and at 250 and $286 \mathrm{~nm}$ for the MDD sample. Besides this, the oligomeric species present on the MDD sample can also be discriminated into two bands at 330 and $380 \mathrm{~nm}$. The relative intensities of these bands are clearly much higher in the MDD sample as compared to the ADP material, enhancing the hypothesis of smaller species present on the ADP sample, as evidenced by the TPR results. The appearance of these separate bands strongly suggests that both synthesis methods do not only yield in a majority of well-dispersed copper oxide species, but also result in diverse types of well-dispersed copper species with different copper coordination and environment. Although the exact structure of these species remains to be investigated, it is expected that these copper oxides will lead to a different behavior during the activity test.

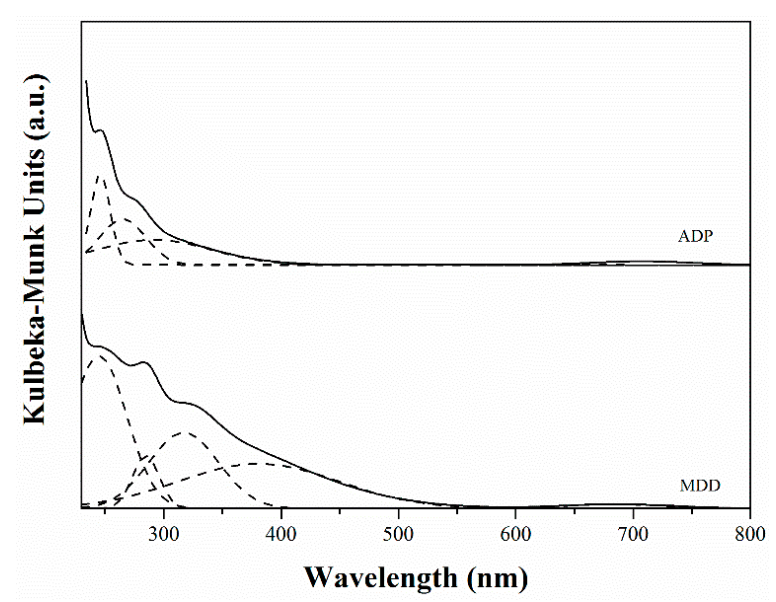

Figure 5. UV-Vis diffuse reflectance spectra of Cu/SBA-15 materials prepared by ADP method (top) and MDD method (bottom).

\subsection{The Formation of Copper Oxide}

The formation of various well-dispersed copper oxide phases on both samples originates from the difference in the $\mathrm{Cu}^{2+}$-support interaction. The reported mechanisms for ammonia-based impregnation 
describe that after the sample is dried, the majority (about 90\%) of $\mathrm{Cu}^{2+}$ on the ADP sample undergoes an ion-exchange process where two $\mathrm{NH}_{3}$ ligands of the copper tetra-ammonia complex are replaced by two $\equiv \mathrm{Si}-\mathrm{O}^{-}$ligands (Figure 6a) [38]. However, in the case of the MDD method, the interaction between the metal acetylacetonate complex and the support is mostly established through hydrogen bonding between acac ligands and the hydride of the surface silanol group (Figure $6 \mathrm{~b}$ left) $[23,24]$. Nevertheless, the interaction via a ligand exchange with the formation of a covalent Me- $\mathrm{O}_{\text {support }}$ bond is also a possible pathway (Figure 6b, right [24]).

(a)

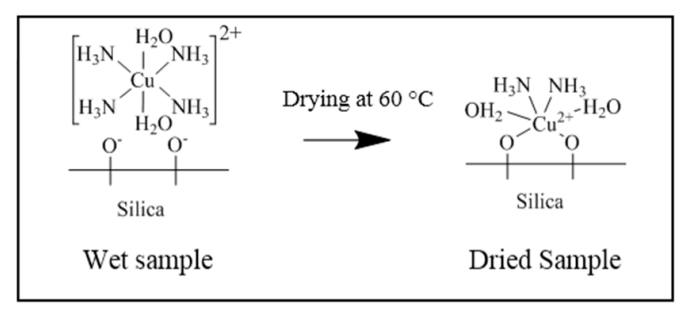

(b)

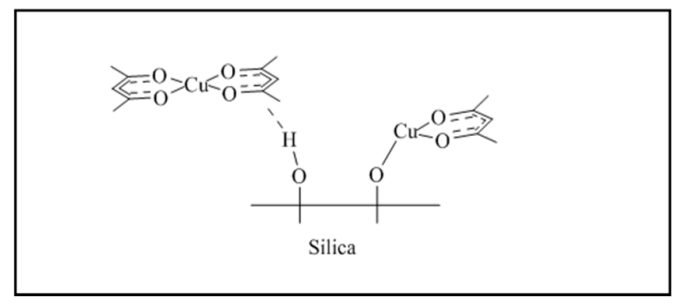

Figure 6. Interactions between $\mathrm{Cu}^{2+}$ species and silica during and after the impregnation for (a) ADP method and (b) MDD method. (Figure 6a: reproduced with permission from Trouillet et al. [38]. Copyright Royal Society of Chemistry, 2000.)

Figure 7 illustrates the result of the differential thermogravimetric (DTG) analysis for the uncalcined MDD sample. It can be noticed that the catalyst demonstrates a sharp weight loss between 180 and $200{ }^{\circ} \mathrm{C}$, associated with a small weight loss from 230 to $500{ }^{\circ} \mathrm{C}$. The weight losses can be assigned respectively to the decomposition of the acac group bonded by hydrogen bonding $\left(\right.$ at $\left.200{ }^{\circ} \mathrm{C}\right)$ and a covalent $\mathrm{Me}-\mathrm{O}_{\text {support }}$ bond $\left(>200^{\circ} \mathrm{C}\right)$ [23]. Thus, the result reveals that the vast majority of the metal-acac complex is interacting with the support through a hydrogen bonding mechanism while only a small part was covalently bonded with the support. In order to confirm this assumption, the $R$-value has been calculated to elucidate the reaction mechanism. The $R$-value is defined as:

$$
R=\frac{\text { (mmol of acac }) /(\mathrm{g} \text { of support })}{(\mathrm{mmol} \text { of } \mathrm{Cu}) /(\mathrm{g} \text { of support })}
$$

herein, the amount of acac ligands can be determined by the weight loss (from 180 to $500{ }^{\circ} \mathrm{C}$ ) in thermogravimetric analysis (TGA) while the content of copper was obtained by electron microprobe analysis (EPMA). The $R$-value for the MDD sample is in our case $1.7 \pm 0.1$, which is close to the number of acetylacetonate ligands present in the parent complex. Therefore, it should be concluded that the $\mathrm{Cu}$-acac complexes react with the surface mainly by hydrogen bonding, resulting in mostly loosely bonded, well-dispersed $\mathrm{CuO}$, evidenced by XPS and $\mathrm{H}_{2}$-TPR. This observation is in contrast with the one reported by the literature which demonstrates a comparable share of both mechanisms in the material [23]. A possible explanation for this deviation between our sample and that from the literature might originate from the washing step which is not performed in our case for maximizing the copper content. For the ADP sample, the DTG curve shows a two-step decomposition occurring at 240 and $260^{\circ} \mathrm{C}$, which respectively corresponds to the decomposition of nitrate originating from the copper precursor and $\mathrm{NH}_{3}$ ligands complexed with $\mathrm{Cu}^{2+}$ [39-41]. 


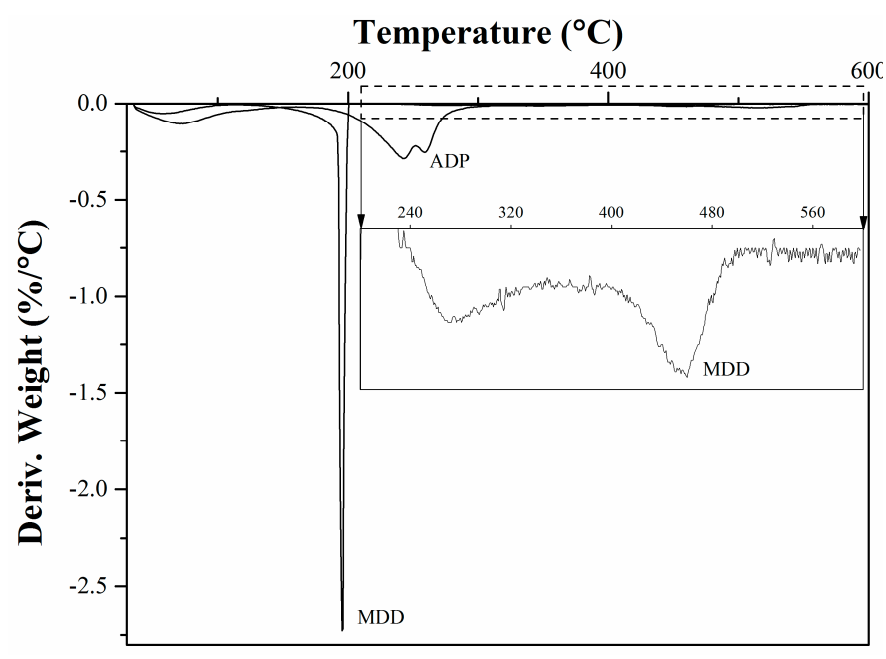

Figure 7. Differential thermogravimetric profiles of $\mathrm{Cu} / \mathrm{SBA}-15$ materials prepared by ADP and MDD methods with the enlargement of the $200-600{ }^{\circ} \mathrm{C}$ region for the MDD sample.

Combining these results and previous observations, the reason for the loosely bonded $\mathrm{CuO}$ formation on the MDD sample can be given. Firstly, it is due to the interaction between the acac ligands and the support's silanol groups through hydrogen bonding. This indirect metal-support interaction limits the formation of $\mathrm{Cu}-\mathrm{O}-\mathrm{Si} \equiv$ during the calcination, resulting in the formation of mainly copper oxides, more weakly bonded to the support surface, as also observed via XPS and $\mathrm{H}_{2}$-TPR. Secondly, since the hydrogen bond is generally a weaker interaction in comparison with the electrostatic interaction (as in ADP), the mobility of the $\mathrm{Cu}^{2+}$ ions can be significantly higher in the MDD sample during the thermal treatment. Thus, this can lead to a partial clustering of the mononuclear copper oxides on the surface during calcination, resulting in larger particles, as observed in UV-DR and suggested by TPR. The overall result is thus the presence of loosely bonded, mononuclear copper oxides and oligomeric copper oxides $\left([\mathrm{Cu}-\mathrm{O}-\mathrm{Cu}]_{n}\right)$ resulting from the agglomeration of mononuclear copper particles due to their low metal-support interaction. In case of the ADP method, the silica dissolution during the deposition and the ionic interactions at play cause a much stronger interaction of the $\mathrm{Cu}$ with the support already in its initial stages of preparation. Moreover, the higher temperature required for the ligand removal warrants a lower mobility of the copper oxide species, postponed to higher temperatures and allowing stronger condensation reactions before its removal and loss of steric hindrance.

\subsection{Catalytic Activity}

To study the influence of various types of $\mathrm{CuO}$ on the catalytic performance, the two catalysts were evaluated under the automotive stoichiometric exhaust gas condition, as shown in Figure 8a,b. The light-off temperature (temperature required for $50 \%$ of reactant's conversion, $T_{50}$ ) and the maximum conversion $\left(C_{\max }\right)$ of each component are summarized in Table 2 . In the case of CO conversion, the sample prepared through the ADP method exhibits a convincible higher activity than the MDD sample, with a maximum conversion of $100 \%$ reached at $300{ }^{\circ} \mathrm{C}$ and a light-off temperature of around $200{ }^{\circ} \mathrm{C}$. On the other hand, the MDD catalyst reached only a maximum conversion of $80 \%$ under the tested conditions, with a light-off temperature of $400{ }^{\circ} \mathrm{C}$, which is two-fold higher than that of the ADP method. A similar trend can be noticed for the HCs oxidation. The ADP sample provides the best performance in all hydrocarbons conversion. Furthermore, in the case of $\mathrm{C}_{3} \mathrm{H}_{6}$, its light-off temperature $\left(\approx 260{ }^{\circ} \mathrm{C}\right)$ is about $65^{\circ} \mathrm{C}$ lower than that of the MDD sample, although both catalysts reached a maximum conversion of $100 \%$. Additionally, the ADP catalyst also demonstrates a convincing $\mathrm{C}_{3} \mathrm{H}_{8}$ oxidation capacity with a maximum conversion of $85 \%$ and $T_{50}$ of $430{ }^{\circ} \mathrm{C}$, while the MDD sample reached only a $C_{\max }$ of $25 \%$ at $500{ }^{\circ} \mathrm{C}$. The MDD sample does seem to lead to a slightly 
better NO reduction activity with a maximum conversion of $8 \%$ at $400{ }^{\circ} \mathrm{C}$ compared to $4 \%$ in the case of ADP.
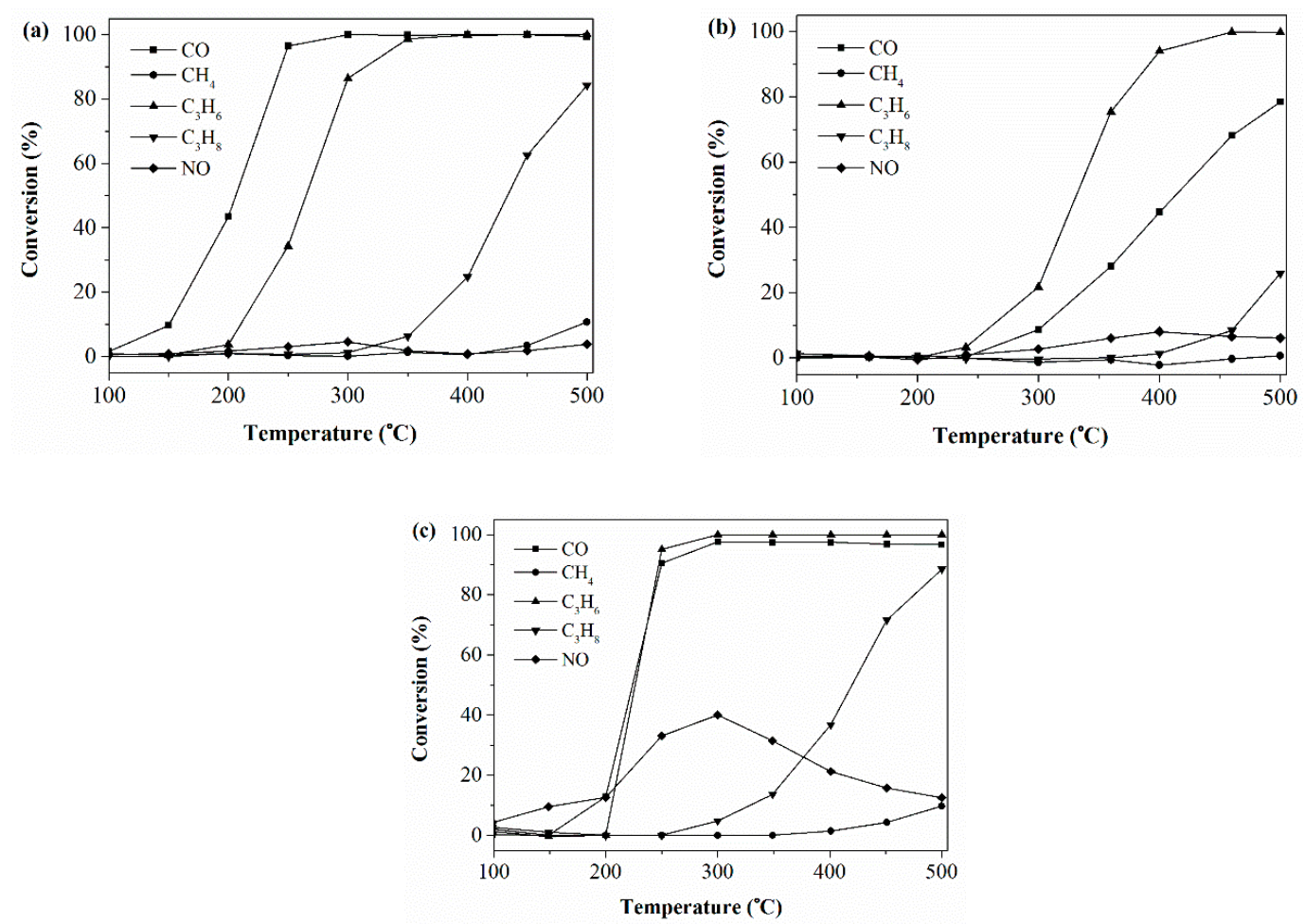

Figure 8. Catalytic performance under stoichiometric condition for $\mathrm{Cu} / \mathrm{SBA}-15$ catalyst prepared by (a) ADP, (b) MDD method and (c) commercial precious metal-loaded three-way catalyst.

Table 2. Light-off temperature $\left(T_{50}\right)$ and maximum conversion $\left(C_{\max }\right)$ of each component for ADP, MDD and three-way catalyst (TWC) catalysts.

\begin{tabular}{|c|c|c|c|c|c|c|c|c|c|c|}
\hline \multirow{2}{*}{ Catalyst } & \multicolumn{2}{|c|}{$\mathrm{CO}$} & \multicolumn{2}{|c|}{$\mathrm{C}_{3} \mathrm{H}_{6}$} & \multicolumn{2}{|c|}{$\mathrm{C}_{3} \mathrm{H}_{8}$} & \multicolumn{2}{|c|}{$\mathrm{CH}_{4}$} & \multicolumn{2}{|c|}{ NO } \\
\hline & $\begin{array}{c}T_{50} \\
\left({ }^{\circ} \mathrm{C}\right)\end{array}$ & $\begin{array}{c}C_{\operatorname{Max}} \\
(\%)\end{array}$ & $\begin{array}{c}T_{50} \\
\left({ }^{\circ} \mathrm{C}\right)\end{array}$ & $\begin{array}{c}C_{\operatorname{Max}} \\
(\%)\end{array}$ & $\begin{array}{c}T_{50} \\
\left({ }^{\circ} \mathrm{C}\right)\end{array}$ & $\begin{array}{c}C_{\operatorname{Max}} \\
(\%)\end{array}$ & $\begin{array}{l}T_{50} \\
\left({ }^{\circ} \mathrm{C}\right)\end{array}$ & $\begin{array}{c}C_{\operatorname{Max}} \\
(\%)\end{array}$ & $\begin{array}{c}T_{50} \\
\left({ }^{\circ} \mathrm{C}\right)\end{array}$ & $\begin{array}{c}C_{\operatorname{Max}} \\
(\%)\end{array}$ \\
\hline MDD & 410 & 80 & 325 & 100 & - & 25 & - & 0.6 & - & 8.0 \\
\hline ADP & 202 & 100 & 260 & 100 & 430 & 85 & - & 10.7 & - & 4.0 \\
\hline TWC & 222 & 100 & 225 & 100 & 370 & 89 & - & 9.7 & - & 40 \\
\hline
\end{tabular}

Hence, despite the presence of highly dispersed $\mathrm{CuO}$ phases obtained via both methods, both catalysts demonstrate a dissimilar catalytic performance: the catalyst prepared by the ADP method represents an improved behavior in $\mathrm{CO}$ and HCs conversion while the MDD sample has a slightly better NO reduction capacity. The divergent results of both catalysts are obviously related to the diverse types of $\mathrm{CuO}$ species on the materials. Combining the previously obtained characterization results, it can be generally derived that $\mathrm{CuO}$ with a strong metal-support interaction seems to promote the automotive oxidation reaction, while the presence of $\mathrm{Cu}(\mathrm{I})$ oxide and weak support-interacting $\mathrm{Cu}$ (II) oxide seems more important for the NO reduction, although its conversion is still very poor.

We took a step further in the catalyst evaluation and compared the ADP sample with a commercial platinum group metal-loaded three-way catalyst (PGM-TWC, Johnson Matthey, Reading, UK) (Figure 8c). The CO conversion of the ADP catalyst shows an outstanding result with a comparable light-off temperature (at $20{ }^{\circ} \mathrm{C}$ ) to the commercial catalyst (Table 2). The maximum conversion towards the propene, propane and methane conversion is also similar between both catalysts, although the light-off temperature is about $40{ }^{\circ} \mathrm{C}$ lower in PGM-TWC than in ADP for propene conversion and even 
$60{ }^{\circ} \mathrm{C}$ lower for propane. On the other hand, the PGM-TWC demonstrates a much higher NO $(40 \%)$ conversion. Here, it is important to mention that the catalytic activity of the standard PGM-TWC is reinforced by the various catalytic promoters present in the material [42], while this is not the case for our $\mathrm{CuO} / \mathrm{SBA}-15$ materials. This means that its behavior is already comparable to the PGM-TWC for some gases and can even be further improved by the addition of promotors and co-catalysts in the future.

\section{Materials and Methods}

\subsection{Support Preparation}

Mesoporous silica SBA-15 was synthesized according to its verified synthesis [43]. Generally, Pluronic P123 triblock copolymer (P123, molecular weight $5800 \mathrm{~g} / \mathrm{mol}$, Sigma Aldrich, Diegem, Belgium) was firstly dissolved in a $1 \mathrm{M}$ aqueous solution of $\mathrm{HCl}$ (37 wt \%, Acros, Geel, Belgium) at $30{ }^{\circ} \mathrm{C}$. After a complete dissolution of the copolymers, the temperature was raised to $40{ }^{\circ} \mathrm{C}$ and tetraethyl orthosilicate (TEOS, Acros) was added dropwise into the solution under vigorous stirring. The final molar composition is $1.0 \mathrm{TEOS} / 0.017 \mathrm{P} 123 / 2.1 \mathrm{HCl} / 116 \mathrm{H}_{2} \mathrm{O}$. After $24 \mathrm{~h}$ of stirring, the gel was hydrothermally treated at $100{ }^{\circ} \mathrm{C}$ for $72 \mathrm{~h}$. The solid was filtered and washed with deionized water and dried at $60^{\circ} \mathrm{C}$ overnight. Finally, the material was calcined at $550{ }^{\circ} \mathrm{C}$ for $6 \mathrm{~h}$ with a heating rate of $1^{\circ} \mathrm{C} \cdot \mathrm{min}^{-1}$ in ambient atmosphere.

\subsection{Catalysts Preparation}

The MDD catalyst was prepared by the adapted molecular designed dispersion method. Prior to the synthesis, the SBA- 15 support was dried at $200^{\circ} \mathrm{C}$ for $6 \mathrm{~h}$ in air. Consequently, $1 \mathrm{~g}$ of the thermally treated support was stirred in $10 \mathrm{~mL}$ anhydrous chloroform solution $\left(\mathrm{CHCl}_{3}, \geq 99 \%\right.$, Sigma Aldrich) containing $1.6 \mathrm{mmol}$ of copper acetylacetonate $\left(\mathrm{Cu}(\mathrm{acac})_{2}, 99 \%\right.$, Acros) in a dry air flushed glove box, to achieve a final $\mathrm{Cu}$ loading of $10 \mathrm{wt} \%$. The whole mixture was stirred for $48 \mathrm{~h}$ at room temperature, followed by a drying step at $60{ }^{\circ} \mathrm{C}$ overnight. The washing and filtration step was skipped in order to maintain the maximum amount of copper loading. Finally, the dried samples were calcined at $550{ }^{\circ} \mathrm{C}$ for $6 \mathrm{~h}$ with a heating rate of $1^{\circ} \mathrm{C} \cdot \mathrm{min}^{-1}$ in ambient temperature.

The ADP catalyst was prepared by an adapted and optimized ADP procedure according to Guo et al. [25]. Typically, $1 \mathrm{~g}$ of SBA-15 support was suspended into a $50 \mathrm{~mL}, 0.03 \mathrm{M}$ aqueous copper nitrate solution $\left(\mathrm{Cu}\left(\mathrm{NO}_{3}\right)_{2} \cdot 3 \mathrm{H}_{2} \mathrm{O},>99 \%\right.$, Merck, Overijse, Belgium) to achieve a $10 \mathrm{wt} \%$ final $\mathrm{Cu}$ loading. Then, ammonia $\left(\mathrm{NH}_{4} \mathrm{OH}, 28 \%-30 \%\right.$, Acros) was added into the mixture to gain a molar $\mathrm{Cu} / \mathrm{NH}_{3}$ ratio of $1 / 6$. The suspension was stirred for $48 \mathrm{~h}$ at room temperature, followed by the same drying and calcination procedure as by MDD (dried at $60^{\circ} \mathrm{C}$ overnight without washing or filtration and calcined at $550{ }^{\circ} \mathrm{C}$ for $6 \mathrm{~h}$ with of $1{ }^{\circ} \mathrm{C} \cdot \mathrm{min}^{-1}$ in ambient atmosphere).

\subsection{Catalysts Characterization}

$\mathrm{N}_{2}$-physisorption was carried out with a Quantachrome Quadrasorb SI automated gas adsorption system. Prior to the measurements, the samples were outgassed at $200^{\circ} \mathrm{C}$ for $16 \mathrm{~h}$. The specific surface area was calculated using the Brunauer-Emmett-Teller (BET) equation. For the metal loaded samples, its specific area was calculated by using the weight of the supports only, excluding the metal content in the total sample weight. The Barret-Joyner-Halenda method was applied to estimate the pore size distribution. The total pore volume was determined at $P / P_{0}=0.95$ while the micro pore volume was obtained via $t$-plot method. Wide angle X-ray diffraction was performed using a Panalytical X'PERT Pro diffractometer (Panalytical, Almelo, The Netherlands) with an anode $X$-ray generator (operating at $40 \mathrm{kV}, 40 \mathrm{~mA}$, Cu-filtered $\mathrm{Cu} \mathrm{K} \alpha$ radiation, scanning speed $\left.0.04^{\circ} / 4 \mathrm{~s}\right)$. UV-Vis diffuse reflectance (UV-Vis-DR) analysis was carried out on a Nicolet Evolution 500 spectrophotometer (ThermoFischer Scientific, Waltham, MA, USA) equipped with an integrating sphere. The spectra were taken in the range of $200-800 \mathrm{~nm}$ with a scan speed of $120 \mathrm{~nm} / \mathrm{min}$. The samples were diluted to $2 \mathrm{wt} \%$ with 
dried KBr. TPR measurements of the catalysts were performed by a Quantachrome iQ (Quantachrome Instrument, Odelzhausen, Germany). About $20 \mathrm{mg}$ of the sample was outgassed at $200{ }^{\circ} \mathrm{C}$ for $16 \mathrm{~h}$. After cooling, the sample was first pretreated at $250{ }^{\circ} \mathrm{C}$ under a He flow for $1 \mathrm{~h}$. Subsequently, the samples were reduced with $5 \mathrm{vol} \% \mathrm{H}_{2} / \mathrm{Ar}$ at a flow rate of $25 \mathrm{~mL} \cdot \mathrm{min}^{-1}$ and the temperature was increased from 50 to $600{ }^{\circ} \mathrm{C}$ with a heating rate of $10^{\circ} \mathrm{C} \cdot \mathrm{min}^{-1}$. The hydrogen consumption was continuously monitored using a thermal conductivity detector (TCD).

The chemical composition of the samples was identified by electron microprobe analysis (EPMA) on a JEOL JXA 733 (JEOL, Peabody, MA, USA). The materials were grinded and dispersed on a copper grid coated with a carbon film. For each sample, three measurement points were taken to calculate the average metal loading. XPS was carried out by means of a PerkinElmer PHI 5600ci Multi Technique System (PerkinElmer, Waltham, MA, USA), using Al K $\alpha$ radiation $(1486.6 \mathrm{eV})$ working at $250 \mathrm{~W}$. The spectrometer was calibrated by assuming the $\mathrm{BE}$ of the $\mathrm{Au} 4 \mathrm{f}_{7 / 2}$ line to be $84.0 \mathrm{eV}$ with respect to the Fermi level. The standard deviation in the BE values of the XPS line is $0.10 \mathrm{eV}$. The peak positions were corrected for the charging effects by considering the $\mathrm{C} 1 \mathrm{~s}$ peak at $285.0 \mathrm{eV}$ and evaluating the BE differences. Thermogravimetric experiments (TGA) were conducted on a Mettler Toledo TA 851 (Mettler Toledo, Zaventem, Belgium). Samples were heated in an oxygen flow from 30 to $600{ }^{\circ} \mathrm{C}$ with a heating rate of $10^{\circ} \mathrm{C} \cdot \mathrm{min}^{-1}$.

\subsection{Catalytic Activity Test}

The catalytic performance of the materials was tested in a fixed bed continuous stainless steel reactor with a gas hourly space velocity of $60,000 \mathrm{~mL} \cdot \mathrm{h}^{-1}$ and a total gas flow rate of $200 \mathrm{NmL} \cdot \mathrm{min}^{-1}$. Prior to the measurement, the catalytic powder was pelletized using an IR pelletizer and crushed in order to have a particle size between 500 and $1000 \mu \mathrm{m}$. The pressure applied to the pelletizer was about $200 \mathrm{MPa}$ which does not affect the textural property of the material [44]. Afterwards, $200 \mathrm{mg}$ of the sieved catalyst was aged by passing atmospheric air $\left(50 \mathrm{~mL} \cdot \mathrm{min}^{-1}\right)$ through the reactor at $500{ }^{\circ} \mathrm{C}$ for $2 \mathrm{~h}$. Consequently, the reactor was cooled to $50{ }^{\circ} \mathrm{C}$ and the catalyst was then exposed to vehicle exhaust gas under stoichiometric condition $(\lambda=1)$ with $0.7 \mathrm{vol} \% \mathrm{CO}, 0.00225 \mathrm{vol} \% \mathrm{CH}_{4}$, 0.045 vol $\% \mathrm{C}_{3} \mathrm{H}_{6}, 15$ vol $\% \mathrm{CO}_{2}, 10$ vol $\% \mathrm{H}_{2} \mathrm{O}, 0.233$ vol $\% \mathrm{H}_{2}, 0.777$ vol $\% \mathrm{O}_{2}$ and 0.1 vol \% NO. The conversion performance was recorded every $50{ }^{\circ} \mathrm{C}$ from 50 to $500{ }^{\circ} \mathrm{C}\left(5^{\circ} \mathrm{C} \cdot \mathrm{min}^{-1}\right)$. For the analysis of the gas stream leaving the reactor, a Shimadzu GC-17A gas chromatograph (Shimadzu, Duisburg, Germany) equipped with FID detector was used for the hydrocarbons conversion analysis. While a Dräger X-am 7000 CO analyzer (Dräger, Lübeck, Germany) was utilized for the CO gas quantification. A ThermoFischer Scientific $\mathrm{NO}_{x}$ analyzer (ThermoFischer Scientific) was also used for monitoring the NO conversion during the catalytic reaction. The catalytic activity of the catalysts was calculated for the conversion of respectively $\mathrm{CO}, \mathrm{CH}_{4}, \mathrm{C}_{3} \mathrm{H}_{6}, \mathrm{C}_{3} \mathrm{H}_{8}$ and $\mathrm{NO}$ in function of the reaction temperature.

\section{Conclusions}

CuO-loaded SBA-15 catalysts have been compared based on two preparation methods known to create a high dispersion degree of metals on the support surface: the molecular designed dispersion (MDD) and ammonia-driven deposition precipitation (ADP) methods. We evaluated the differences in structural and textural properties, as well as the copper dispersion state of both materials and revealed the differences in the formed $\mathrm{CuO}$ phase on the support.

XPS spectra revealed the existence of $\mathrm{Cu}^{2+}$ on both materials' surfaces, which can be further divided into two entities: The sample prepared by the ADP method consists of copper phyllosilicate and copper oxide/hydroxide distributed on the surface. On the other hand, mainly copper oxide/hydroxide particles are evidenced on the MDD sample. $\mathrm{H}_{2}$-TPR showed that the ADP method results in the formation of the $\mathrm{CuO}$ phase with a smaller size and/or a stronger metal-support interaction brought by the phyllosilicate and grafted copper formation, while the MDD approach provides mainly well-dispersed $\mathrm{CuO}$, loosely bonded on the SBA-15 surface. Such deviations are explained by the complex-support interaction during the synthesis, which is an electrostatic interaction 
in the case of ADP and a hydrogen-bonding interaction in the case of MDD, as well as the temperatures of ligand removal. Moreover, the UV-Vis-DR characterization of the individual samples pointed to a more complex copper composition on the catalysts. For both samples, the UV-Vis-DR spectrum revealed at least two different species within the monomeric copper oxide and a clear presence of various oligomeric species in case of the MDD sample. Although further investigation is necessary to unravel the exact identity of these structures, it is a fact that those entities have a strong influence on the material's catalytic activity: CuO/SBA-15 by ADP demonstrated an outstanding oxidation activity towards the automotive emission abatement, whereas a slightly higher NO conversion was assessed for the MDD sample. Furthermore, the ADP sample has a comparable oxidation activity as the commercial TWC for CO and a slightly inferior activity for hydrocarbons, even without the presence of promotors. Besides this, the ADP material is expected to have an enhanced thermal stability compared to the MDD sample since the strong metal-support interaction will suppress the mobility of copper particles at elevated temperature. These results provide strong evidence that copper can be used for precious metal replacement in the automotive catalyst by using an appropriate preparation method such as the ADP approach. The importance of the local structure of the copper oxide clusters that are present has been clearly demonstrated. However, since SBA-15 is not the most optimal candidate for the support due to its low hydrothermal stability [44], future work identifying a more robust and stable support, as well as further catalyst optimization, will be necessary.

Acknowledgments: The authors kindly acknowledge the EU-FP 7 Next-Gen-Cat project (grant agreement number: 280890) for its financial support. Johnson Matthey is also acknowledged for providing the commercial precious metal loaded three-way catalyst.

Author Contributions: Qi Xin conceived and designed the experiments; Qi Xin and Jeff L. Nyalosaso performed the experiments; Antonella Glisenti performed and analyzed the XPS data; Constantine Philippopoulos and Evangelos Poulakis conducted and performed the catalytic performance tests; Myrjam Mertens performed and analyzed the XRD data; Qi Xin analyzed the data; Qi Xin wrote the paper; Antonella Glisenti, Vera Meynen and Pegie Cool guided the work, modified the paper and discussed the results and explanations.

Conflicts of Interest: The authors declare no conflict of interest.

\section{References}

1. Twigg, M.V. Catalytic control of emissions from cars. Catal. Today 2011, 163, 33-41. [CrossRef]

2. Muroi, T. Role of precious metal catalysts. In Noble Metals; Su, Y.H., Ed.; InTech: Rijeka, Croatia, 2012; pp. 301-330.

3. Matthey, J. Forecast of Platinum Supply \& Demands in 2014. Available online: www.platinum.matthey.com/ documents/new-item/pgm\%20market\%20reports/pgm\%20market\%20report\%20november\%202015. pdf\&usg=AFQjCNFcHLV5hPhuFOyFS2G7119nhZEWBA\&sig2=ZjbjI1fYY11VzQXbAezbNg\&cad=rja (accessed on 22 August 2016).

4. Fechete, I.; Wang, Y.; Védrine, J.C. The past, present and future of heterogeneous catalysis. Catal. Today 2012, 189, 2-27. [CrossRef]

5. Ertl, G.; Knozinger, H.; Schutl, F.; Weitkamp, J. Handbook of Heterogenous Catalysis, 2nd ed.; Wiley-VCH: Weinheim, Germany, 2008; pp. 2237-2331.

6. López-Suárez, F.E.; Bueno-López, A.; Illán-Gómez, M.J. Cu/ $\mathrm{Al}_{2} \mathrm{O}_{3}$ catalysts for soot oxidation: Copper loading effect. Appl. Catal. B 2008, 84, 651-658. [CrossRef]

7. Kummer, J.T. Catalysts for automobile emission control. Prog. Energy Combust. Sci. 1980, 6, 177-199. [CrossRef]

8. Vila, F.; López Granados, M.; Ojeda, M.; Fierro, J.L.G.; Mariscal, R. Glycerol hydrogenolysis to 1,2-propanediol with $\mathrm{Cu} / \gamma-\mathrm{Al}_{2} \mathrm{O}_{3}$ : Effect of the activation process. Catal. Today 2012, 187, 122-128. [CrossRef]

9. Zhu, S.; Gao, X.; Zhu, Y.; Fan, W.; Wang, J.; Li, Y. Highly efficient and robust $\mathrm{Cu} / \mathrm{SiO}_{2}$ catalyst prepared by the ammonia evaporation hydrothermal method for glycerol hydrogenolysis to 1,2-propanediol. Catal. Sci. Technol. 2015, 5, 1169-1180. [CrossRef] 
10. Huang, Z.; Cui, F.; Kang, H.; Chen, J.; Xia, C. Characterization and catalytic properties of the CuO/SiO 2 catalysts prepared by precipitation-gel method in the hydrogenolysis of glycerol to 1,2-propanediol: Effect of residual sodium. Appl. Catal. A 2009, 366, 288-298. [CrossRef]

11. Chen, L.; Guo, P.; Qiao, M.; Yan, S.; Li, H.; Shen, W.; Xu, H.; Fan, K. Cu/SiO 2 catalysts prepared by the ammonia-evaporation method: Texture, structure, and catalytic performance in hydrogenation of dimethyl oxalate to ethylene glycol. J. Catal. 2008, 257, 172-180. [CrossRef]

12. Li, F.; Lu, C.-S.; $\mathrm{Li}, \mathrm{X}$.-N. The effect of the amount of ammonia on the $\mathrm{Cu}^{0} / \mathrm{Cu}^{+}$ratio of $\mathrm{Cu} / \mathrm{SiO}_{2}$ catalyst for the hydrogenation of dimethyl oxalate to ethylene glycol. Chinese Chem. Lett. 2014, 25, 1461-1465. [CrossRef]

13. Zhu, Y.Y.; Wang, S.R.; Zhu, L.J.; Ge, X.L.; Li, X.B.; Luo, Z.Y. The influence of copper particle dispersion in $\mathrm{Cu} / \mathrm{SiO}_{2}$ catalysts on the hydrogenation synthesis of ethylene glycol. Catal. Letters 2010, 135, $275-281$. [CrossRef]

14. van den Berg, R.; Parmentier, T.E.; Elkjær, C.F.; Gommes, C.J.; Sehested, J.; Helveg, S.; de Jongh, P.E.; de Jong, K.P. Support functionalization to retard ostwald ripening in copper methanol synthesis catalysts. ACS Catal. 2015, 5, 4439-4448. [CrossRef]

15. Kasatkin, I.; Kurr, P.; Kniep, B.; Trunschke, A.; Schlögl, R. Role of lattice strain and defects in copper particles on the activity of $\mathrm{Cu} / \mathrm{ZnO} / \mathrm{Al}_{2} \mathrm{O}_{3}$ catalysts for methanol synthesis. Angew. Chemie Int. Ed. 2007, 46, 7324-7327. [CrossRef] [PubMed]

16. Zuo, Z.J.; Wang, L.; Han, P.D.; Huang, W. Methanol synthesis by $\mathrm{CO}$ and $\mathrm{CO}_{2}$ hydrogenation on $\mathrm{Cu} / \gamma-\mathrm{Al}_{2} \mathrm{O}_{3}$ surface in liquid paraffin solution. Appl. Surf. Sci. 2014, 290, 398-404. [CrossRef]

17. Jos van Dillen, A.; Terorde, R.; Lensveld, D.J.; Geus, J.W.; de Jong, K.P. Synthesis of supported catalysts by impregnation and drying using aqueous chelated metal complexes. J. Catal. 2003, 216, 257-264. [CrossRef]

18. Twigg, M.V.; Spencer, M.S. Deactivation of supported copper metal catalysts for hydrogenation reactions. Appl. Catal. A 2001, 212, 161-174. [CrossRef]

19. Prieto, G.; Zečević, J.; Friedrich, H.; de Jong, K.P.; de Jongh, P.E. Towards stable catalysts by controlling collective properties of supported metal nanoparticles. Nat. Mater. 2013, 12, 34-39. [CrossRef] [PubMed]

20. Farmer, J.A.; Campbell, C.T. Ceria maintains smaller metal catalyst particles by strong metal-support bonding. Science 2010, 329, 933-936. [CrossRef] [PubMed]

21. Kenvin, J.C.; White, M.G.; Mitchell, M.B. Preparation and characterization of supported mononuclear metal complexes as model catalysts. Langmuir 1991, 7, 1198-1205. [CrossRef]

22. Lindblad, M.; Peter, L.; Suntola, T. Preparation of Ni/ $\mathrm{A}_{2} \mathrm{O}_{3}$ catalysts from vapor phase by atomic layer epitaxy. Catal. Letters 1994, 27, 323-336. [CrossRef]

23. Kuśtrowski, P.; Chmielarz, L.; Dziembaj, R.; Cool, P.; Vansant, E.F. Modification of MCM-48-, SBA-15-, MCF-, and MSU-type mesoporous silicas with transition metal oxides using the molecular designed dispersion method. J. Phys. Chem. B 2005, 109, 11552-11528. [CrossRef] [PubMed]

24. Segura, Y.; Cool, P.; Van Der Voort, P.; Mees, F.; Meynen, V.; Vansant, E.F. TiO $x-\mathrm{VO}_{x}$ mixed oxides on SBA-15 support prepared by the designed dispersion of acetylacetonate complexes: Spectroscopic study of the reaction mechanisms. J. Phys. Chem. B 2004, 108, 3794-3800. [CrossRef]

25. Guo, X.; Yin, A.; Dai, W.L.; Fan, K. One pot synthesis of ultra-high copper contented Cu/SBA-15 material as excellent catalyst in the hydrogenation of dimethyl oxalate to ethylene glycol. Catal. Letters 2009, 132, $22-27$. [CrossRef]

26. Jiao, L.; Regalbuto, J.R. The synthesis of highly dispersed noble and base metals on silica via strong electrostatic adsorption: I. Amorphous silica. J. Catal. 2008, 260, 329-341. [CrossRef]

27. Toupance, T.; Kermarec, M.; Louis, C. Conditions of formation of copper phyllosilicates in silica-supported copper catalysts prepared by selective adsorption. J. Phys. Chem. B 2002, 106, 2277-2286. [CrossRef]

28. Dziembaj, R.; Cool, P.; Vansant, E.F. Catalytic performance of various mesoporous silicas modified with copper or iron oxides introduced by different ways in the selective reduction of NO by ammonia. Appl. Catal. B 2006, 62, 369-380.

29. García-Trenco, A.; Martínez, A. A simple and efficient approach to confine $\mathrm{Cu} / \mathrm{ZnO}$ methanol synthesis catalysts in the ordered mesoporous SBA-15 silica. Catal. Today 2013, 215, 152-161. [CrossRef]

30. Thommes, M.; Kaneko, K.; Neimark, A.V.; Olivier, J.P.; Rodriguez-Reinoso, F.; Rouquerol, J.; Sing, K.S.W. Physisorption of gases, with special reference to the evaluation of surface area and pore size distribution (IUPAC Technical Report). Pure Appl. Chem. 2015, 87, 1051-1069. [CrossRef] 
31. Prieto, G.; Shakeri, M.; de Jong, K.P.; de Jongh, P.E. Quantitative relationship between support porosity and the stability of pore-confined metal nanoparticles studied on $\mathrm{CuZnO} / \mathrm{SiO}_{2}$ methanol synthesis catalysts. ACS Nano 2014, 8, 2522-2531. [CrossRef] [PubMed]

32. Van Der Grift, C.J.G.; Elberse, P.A.; Mulder, A.; Geus, J.W. Preparation of silica-supported copper catalysts by means of deposition-precipitation. Appl. Catal. 1990, 59, 275-289. [CrossRef]

33. Toupance, T.; Kermarec, M.; Louis, C. Metal particle size in silica-supported copper catalysts. Influence of the conditions of preparation and of thermal pretreatments. J. Phys. Chem. B 2000, 104, 965-972. [CrossRef]

34. Huang, Z.; Cui, F.; Xue, J.; Zuo, J.; Chen, J.; Xia, C. Cu/SiO 2 catalysts prepared by hom- and heterogeneous deposition-precipitation methods: Texture, structure, and catalytic performance in the hydrogenolysis of glycerol to 1,2-propanediol. Catal. Today 2012, 183, 42-51. [CrossRef]

35. Zhang, B.; Hui, S.; Zhang, S.; Ji, Y.; Li, W.; Fang, D. Effect of copper loading on texture, structure and catalytic performance of $\mathrm{Cu} / \mathrm{SiO}_{2}$ catalyst for hydrogenation of dimethyl oxalate to ethylene glycol. J. Nat. Gas Chem. 2012, 21, 563-570. [CrossRef]

36. Khodakov, A.Y.; Lynch, J.; Bazin, D.; Rebours, B.; Zanier, N.; Moisson, B.; Chaumette, P. Reducibility of cobalt species in silica-supported Fischer-Tropsch catalysts. J. Catal. 1997, 168, 16-25. [CrossRef]

37. Praliaud, H.; Mikhailenko, S.; Chajar, Z.; Primet, M. Surface and bulk properties of Cu-ZSM-5 and $\mathrm{Cu} / \mathrm{Al}_{2} \mathrm{O}_{3}$ solids during redox treatments. Correlation with the selective reduction of nitric oxide by hydrocarbons. Appl. Catal. B 1998, 16, 359-374. [CrossRef]

38. Trouillet, L.; Toupance, T.; Villain, F.; Louis, C. In situ characterization of the coordination sphere of Cu II complexes supported on silica during the preparation of $\mathrm{Cu} / \mathrm{SiO}_{2}$ catalysts by cation exchange. Phys. Chem. Chem. Phys. 2000, 2, 2005-2014. [CrossRef]

39. Munnik, P.; Wolters, M.; Gabrielsson, A.; Pollington, S.D.; Headdock, G.; Bitter, J.H.; de Jongh, P.E.; de Jong, K.P. Copper nitrate redispersion to arrive at highly active silica-supported copper catalysts. J. Phys. Chem. C 2011, 115, 14698-14706. [CrossRef]

40. Ryu, S.K.; Lee, W.K.; Park, S.J. Thermal decomposition of hydrated copper nitrate $\left[\mathrm{Cu}\left(\mathrm{NO}_{3}\right)_{2} \cdot 3 \mathrm{H}_{2} \mathrm{O}\right]$ on activated carbon fibers. Carbon Sci. 2004, 5, 180-185.

41. De Dobbelaere, C.; Mullens, J.; Hardy, A.; Van Bael, M.K. Thermal decomposition and spectroscopic investigation of a new aqueous glycolato(-peroxo) Ti(IV) solution-gel precursor. Thermochim. Acta 2011, 520, 121-133. [CrossRef]

42. Farrauto, R.J.; Bartholomew, C.H. Evironmetnal catalysis: Mobile souces. In Fundamentals of Industrial Catalytic Processes; Wiley: New York, NY, USA, 2004; pp. 705-741.

43. Meynen, V.; Cool, P.; Vansant, E.F. Verified syntheses of mesoporous materials. Microporous Mesoporous Mater. 2009, 125, 170-223. [CrossRef]

44. Smeulders, G.; Meynen, V.; Silvestre-Albero, A.; Houthoofd, K.; Mertens, M.; Silvestre-Albero, J.; Martens, J.A.; Cool, P. The impact of framework organic functional groups on the hydrophobicity and overall stability of mesoporous silica materials. Mater. Chem. Phys. 2012, 132, 1077-1088. [CrossRef]

(C) 2016 by the authors; licensee MDPI, Basel, Switzerland. This article is an open access article distributed under the terms and conditions of the Creative Commons Attribution (CC-BY) license (http://creativecommons.org/licenses/by/4.0/). 